\title{
Motivations for muon radiography of active volcanoes
}

\author{
G. Macedonio and M. Martini \\ Istituto Nazionale di Geofisica e Vulcanologia, Osservatorio Vesuviano, Napoli, Italy \\ (Received December 5, 2008; Revised March 3, 2009; Accepted March 30, 2009; Online published February 22, 2010)
}

\begin{abstract}
Muon radiography represents an innovative tool for investigating the interior of active volcanoes. This method integrates the conventional geophysical techniques and provides an independent way to estimate the density of the volcano structure and reveal the presence of magma conduits. The experience from the pioneer experiments performed at Mt. Asama, Mt. West Iwate, and Showa-Shinzan (Japan) are very encouraging. Muon radiography could be applied, in principle, at any stratovolcano. Here we focus our attention on Vesuvius and Stromboli (Italy).
\end{abstract}

Key words: Volcanic structure, muon radiography, Vesuvius, Stromboli, Asama volcano, MU-RAY experiment.

\section{Introduction}

The dynamics of active volcanoes is controlled by many factors, including magma chemical composition, gas content, depth and dimensions of the magmatic reservoir, geometry of the magmatic conduits, and physical characteristics of the volcanic structure. Usually, information on the storage system and the composition of magma is based on the chemical analysis of the products of past eruptions. In fact, the nature of the erupted material carries information about the magma storage. The eruptive style (explosive or effusive) is a rst qualitative indicator of the quantity of the gas dissolved in the magma, being lower for effusive and higher for explosive eruptions. The chemical analysis of the glassy part of the magma and of the uid inclusions captured by the crystals during their residence inside the magma reservoir allows the quantity of the dissolved gas to be estimated and, in addition, the contacts between the glassy part of magma and the crystals provides information on the temperature and pressure during crystals growth (see Scaillet et al., 2008 and references therein). The magmatic pressure is often related to the depth of the reservoir (typically around a few $\mathrm{km}$ ) through the simple hydrostatic law $\left(d P / d z=-\rho_{\mathrm{c}} g\right)$, where $P$ is the pressure at a given depth, $\rho_{\mathrm{c}}$ is the density of the country rock above the reservoir, $g$ is the gravity constant, and $z$ is the vertical coordinate (taken positive upward).

During their life, volcanoes often alternate between eruptions characterized by the formations of fractures through which magma reaches the surface and spreads and periods of quiescence in the closed-conduit condition, as observed for Mt. Vesuvius (Italy) and Mt. Asama (Japan). Alternatively, volcanoes show persistent activity with frequent eruptions of small intensity, such as Stromboli or Vesuvius itself in the period between 1631 and 1944.

Copyright (c) The Society of Geomagnetism and Earth, Planetary and Space Sciences (SGEPSS); The Seismological Society of Japan; The Volcanological Society of Japan; The Geodetic Society of Japan; The Japanese Society for Planetary Sciences; TERRAPUB.

doi:10.5047/eps.2009.03.005
The internal structure of a volcano, especially in the upper part, is a product of past eruptions and typically features many superposed layers and remnants. Of course, the knowledge of the internal structure of the volcano is of paramount importance for understanding its behaviour and for forecasting the nature and style of the next eruption. For this reason, in parallel with the analysis of past eruptions, much effort has been extended in past years in experiments investigating the interior of the volcanoes (e.g. Vesuvius) with different techniques, including deep drilling (Cassano and La Torre, 1987; Principe et al., 1987), passive (Scarpa et al., 2002) and active (Zollo et al., 1996, 2002) seismic tomography, geoelectrics and magnetotellurics (Di Maio et al., 1998) and gravimetry (Cella et al., 2007). Each of these methods has its own characteristic advantages and drawbacks, and a complete description of the volcano interior can be achieved only through a synthesis of combined investigations with all the available techniques. One of the limits of conventional geophysical methods is the spatial resolution, which typically ranges between some tens of meters up to $1 \mathrm{~km}$. Although this approach is very important to detect the presence of large magmatic reservoirs, it is inadequate to detect small magma bodies or magma conduits.

In this sense, the radiography of active volcanoes based on natural muons, even if limited to the external part of the volcano, represents an important tool for investigating the internal structure of the volcano at higher spatial resolution.

The experiment of muon radiography carried out at Mt. Asama volcano (Tanaka et al., 2007c) allowed the reconstruction of the density map of the cone and detection of a dense region that corresponds to the position and shape of a lava dome created during the last eruption in 2004. Using a detector of $0.4 \mathrm{~m}^{2}$, at a distance of $1 \mathrm{~km}$, it was possible to reach an angular resolution of $10 \mathrm{mrad}$, which corresponds to about $10 \mathrm{~m}$ in spatial resolution: a limit quite impossible to reach actually with other geophysical techniques due to the strong structural heterogeneities. Moreover, muon radiography is able to resolve density contrasts of the order 
of $1-3 \%$, significantly greater than the resolution obtained with conventional methods (Tanaka et al., 2007c).

Although the muon radiography can be applied to any volcano, in this paper we will focus our attention on Mt. Vesuvius and Stromboli (Italy).

\section{Previous Experiments of Muon Radiography on Active Volcanoes}

Muon radiography is a new technique that is used to produce an image of the volcano interior. The imaging method is, in principle, the same as the X-ray radiography used in medical settings, except for the substitution of penetrating cosmic muons in lieu of X-rays (Tanaka et al., 2003). Experiments on volcanoes were performed on Mt. West Iwate (Tanaka et al., 2003, 2005), Mt. Asama (Tanaka et al., 2007a, b) and Showa-Shinzan (Tanaka et al., $2007 b$ ) in Japan. The muon receptor is placed in the shadow of the volcano for the incoming muon stream, thereby enabling the imaging of the structure crossed by muons. Since cosmic-ray muons are particles generated in the atmosphere that continuously bombard the earth's surface, the radiography can be performed everywhere at anytime on Earth. The muons interact with electrons and nucleons and the number of muon interactions with matter increases proportional to the "density length" (density $\times$ path length). Thus, muon interactions produce an attenuation of the muon flux along paths across the volcano interior which is proportional to the density of the encountered rocks (Tanaka et al., 2007a). The effect of the path length is accounted for by geometrical consideration, using an accurate digital elevation model of the volcano (a 5-m resolution model is available for Vesuvius). Moreover, Monte Carlo simulations of particle tracking is often performed to define the particle flux on the detector, accounting also for the zenith angle distribution of the flux and energy of the incoming muons (Tanaka et al., 2007a). In fact, given that the flux of muons (with a given energy) is lower for muons coming from near-horizontal di- rections, the radiographic images need to be corrected to produce the rock density maps.

Two months of observations at Mt. Asama allowed the detection of density contrasts of 1-2\% within a thickness of rock of a few hundreds meters, with a spatial resolution of $30 \mathrm{~m}$ verticallly and $60 \mathrm{~m}$ horizontally. However, these limits depend on the number of muons detected and can be improved using larger detectors (Tanaka et al., 2007c).

The density maps obtained by Tanaka et al. (2007c) reveal the presence of the lava dome formed inside the crater in 2004, and allow an estimation of a bulk density of 2.76$2.84 \mathrm{~g} / \mathrm{cm}^{3}$ for the lava, and $2.27-2.33 \mathrm{~g} / \mathrm{cm}^{3}$ for the surrounding rocks.

\section{Motivations for Muon-Radiography at Vesu- vius}

Mt. Vesuvius is considered to be one of the most dangerous volcanoes in the world because of the densely inhabited area around its flanks. It is estimated that about 600,000 people would have to be evacuated in the case of volcanic reactivation.

The actual cone of Mt. Vesuvius, $1280 \mathrm{~m}$ a.s.1., grew within the ancient caldera of Mt. Somma after the AD 79 Pompei eruption (Cioni et al., 2008). The northern ridge of the Mt. Somma caldera is the only remaining part of the ancient structure, whose collapse started during two large eruptions occurring about 18,000 and 16,000 years ago. The history of Mt. Vesuvius is characterized by dramatic plinian and sub-plinian eruptions, the most famous of which caused the destruction of the towns of Pompei, Herculaneum and Stabiae in AD 79, as reported by Pliny the Younger. In relatively recent times several eruptions have occurred, with the most recent being in 1944. The eruptions have dramatically altered the morphology of the mountain from what it is assumed to have been before the AD 79 eruption. At present the monitoring system does not reveal signs of notable activity. A correlation has been ob-

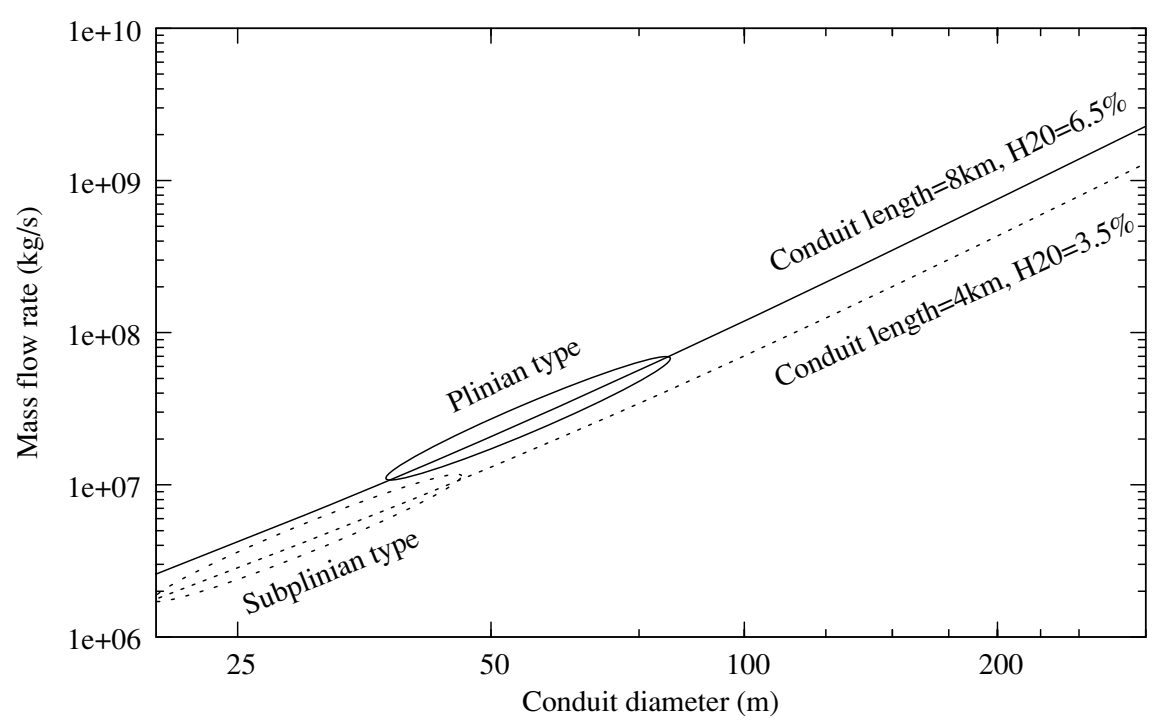

Fig. 1. Simulation of the mass eruption rate of explosive eruptions at Vesuvius vs. conduit diameter, for a gas content $5 \%$ in weight and a conduit length of $8 \mathrm{~km}$. The ranges of sub-Plinian type (1631 eruption) and Plinian type (Pompei) eruptions are shown. 


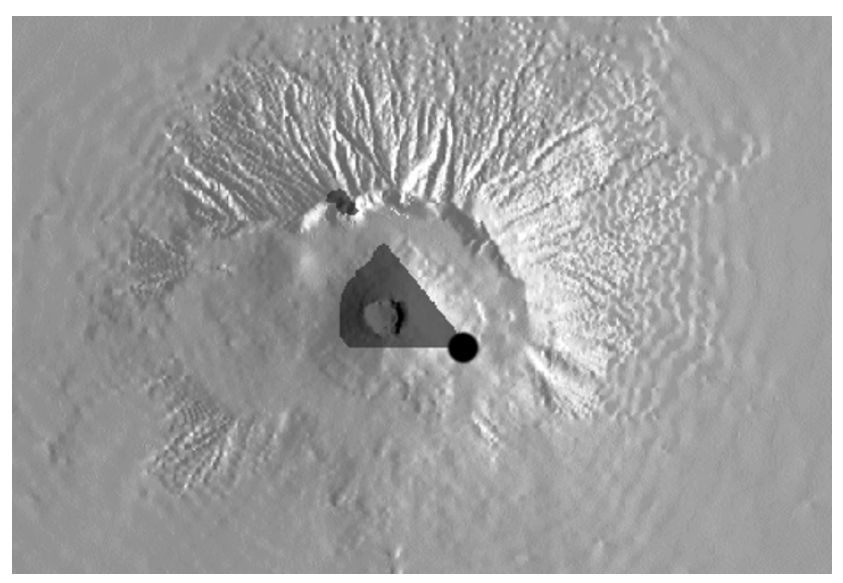

Fig. 2. Shaded relief of the Vesuvius edi ce. The dot shows one of the preferred locations for installing a cosmic-muons detector (Bunker Est); the dark area represents a possible eld of view of the detector. A small volume of Mount Somma rim (at north) could be invested by near horizontal muons.

served between the duration of repose and the strength of an eruption (Santacroce, 1983). The present apparent quiescence raises questions about the amount of stored energy that could be delivered in a future eruption. Moreover, the intensity of an eruption is strongly controlled by the dimensions of the conduit connecting the magma reservoir to the surface (Macedonio et al., 2005). Figure 1 shows the results of the simulation of the mass ow rate of an explosive eruption versus conduit diameter under two different conditions: one representative of Plinian eruptions, similar to the AD 79 eruption with a conduit length of $8 \mathrm{~km}$ and gas content of $6.5 \mathrm{wt} \%$, and one representative of Subplinian eruptions, similar to the AD 472 and AD 1631 eruptions with a conduit length of $4 \mathrm{~km}$ and gas content of $3.5 \mathrm{wt} \%$ (see Cioni et al., 2008 for the physical and compositional parameters of the main eruption types at Vesuvius). The model (Macedonio et al., 2005) assumes a circular conduit and accounts for the transition between bubbly ow and drop ow after magma fragmentation. Figure 1 also shows the range of mass ow rates and conduit diameters for the Plinian eruption in AD 79 (Pompei eruption) and for the sub-Plinian eruption in AD 1631. As can be noted, all other parameters being xed, an increase in the conduit diameter leads to a dramatic increase in the intensity of an explosive eruption. Knowledge of the conduit structure is thus of paramount importance for the establishment of realistic scenarios of a future eruption through accurate simulations of the magma upraising mechanism. Moreover, an independent method for investigating the volcano interior is also needed to better constrain the inverse methods used in processing data from geophysical soundings.

The feasibility of a radiography of the Vesuvius cone using cosmic-ray muons was discussed at the MU-RAY Workshop (MU-RAY, 2008) in Naples, Italy. In Fig. 2, a possible location for a cosmic ray detector at Vesuvius is shown. This site (Bunker Est, $860 \mathrm{~m}$ a.s.1.) was selected both for logistics reasons and as a result of the analysis of the optimal point of view; it represents the best combination of a wide angle of view, spatial resolution, depth of the

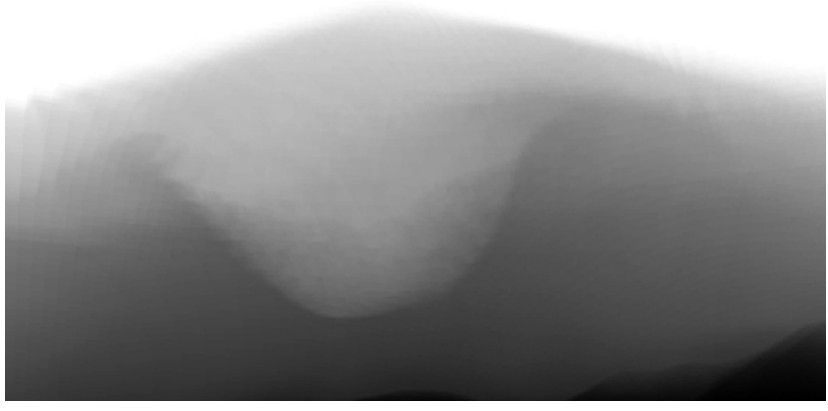

Fig. 3. Simulated density length seen by a detector located at Bunker Est (Vesuvius). Since the density of the rock is here assumed constant, darker colours represent larger paths under ground. The crater of Vesuvius is clearly visible.

travelled body, acquisition time and scienti c interest.

It is expected that the muon radiography would reveal the internal structure of the cone and, possibly, the presence of the magmatic conduits that fed past eruptions. Most of the cone of Vesuvius results from the superposition of numerous layers of pyroclastic material and lava ows that erupted after the eruption of 472 . The upper part of the cone was formed during the persistent activity between 1631 and 1944, when Vesuvius was in the open-conduit state. A reconstruction of the morphology of the Vesuvius cone in the period between 1631 and 1944 was generated by Scarpato et al. (2005), based on a rich collection of historical pictures of the volcano (Ricciardi, 2005).

The conditions of the detectability of the residual conduits are related to their dimensions, shape and density contrast with the surrounding material. Volcanic conduits assume their typical circular shape only near the surface. At greater depths, the common shape of a magma conduit resembles a lled ssure, better as a "dike". The underlying mechanisms that induce the transition between at and circular conduits are not yet completely investigated, and volcano radiography could also provide information for understanding such a process.

Figure 3 shows a simulated map of density length seen by the detector located at Bunker Est (Fig. 2), assuming a constant density of the rock. This simple representation does not account for the distribution of the number of incident muons and energy versus zenith angle or for the adsorption functions of muons in the rock.

\section{Motivations for Muon-Radiography at Stromboli}

Stromboli is located in the Tyrrenian sea and belongs to the Aeolian arc off the southern coast of Italy. Its elevation is approximately $2,500 \mathrm{~m}$ from the sea oor, with its summit $924 \mathrm{~m}$ a.s.l. (Bertagnini et al., 2003). The volcano is considered to be one of the most active in the world. Its moderate but persistent activity started between the 3rd and the 7th centuries AD, consists of continuous degassing, mild explosions (the so called "Strombolian activity"), rare lava emissions, and sporadic violent explosions (Bertagnini 


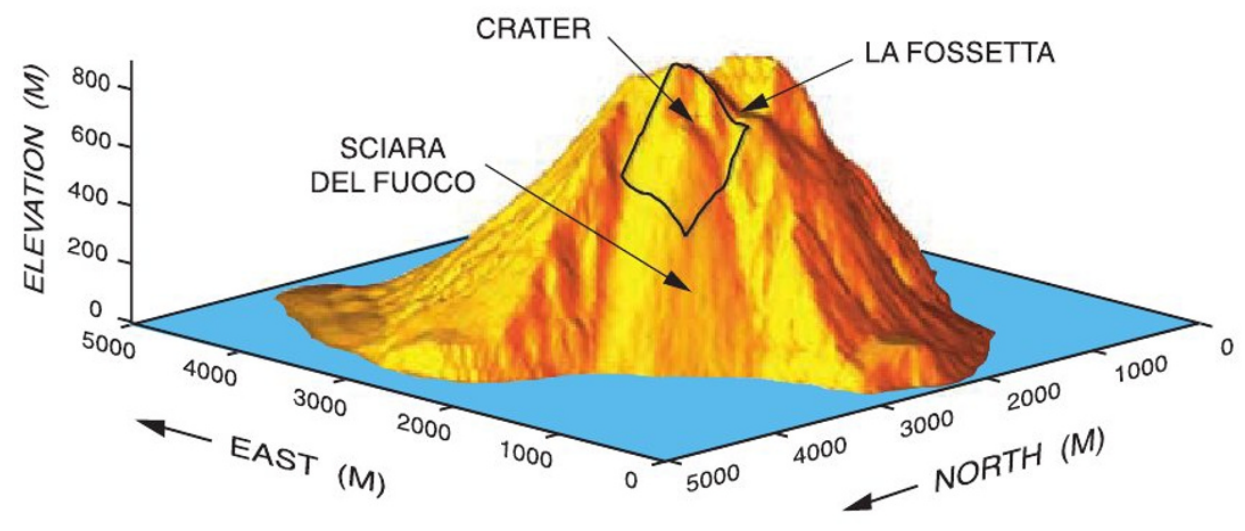

Fig. 4. A south-east looking view of Stromboli. The "Sciara del Fuoco" structure and the active craters are indicated. Inversion of the Very Long Period (VLP) events generated by the volcanic explosions reveal a seismic source constituted by an oscillating dyke located between 220 and $260 \mathrm{~m}$ below the craters. (After Chouet et al., Source mechanisms of explosions at Stromboli Volcano, Italy, determined from moment-tensor inversion of very-long period data, J. Geophys. Res., 108(B1), doi:10.1029/2002JB001919, 2003. Copyright 2003 American Geophysical Union. Reproduced by permission of American Geophysical Union.)

et al., 2003). The intermittent explosions emit jets of gas laden with scoria, ash and volcanic bombs every 10-20 min. Most of the erupted material fall in the "Sciara del Fuoco" (Fig. 4): a horse-shaped structure representing the scar of several flank collapses (Tibaldi, 2001). On December 30, 2002, after several months of strong explosive activity at the summit crater, the collapse of a large portion of Sciara del Fuoco triggered a tsunami that caused significant damage along the coast of the island up to $10 \mathrm{~m}$ a.s.l. (Bonaccorso et al., 2003). The flank collapse was followed by the opening of an eruptive vent and the production of a lava flow that lasted for 6 months. During the effusive activity, a paroxysmal explosion on April 5, 2003 launched volcanic bombs up to $4 \mathrm{~m}$ in diameter on the nearby village of Ginostra. These events triggered strong action by the Department of Civil Defence to reduce the risk for the inhabitants and tourists. Moreover, the monitoring system was significantly improved, resulting today in one of the most advanced surveillance network on active volcanoes in the world. In particular, a new seismic network was installed, on the basis of previous studies and experiments with broadband seismic stations performed at Stromboli in September 1997 (Chouet et al., 2003). The great amount of collected data allowed a quantification of the source mechanism of Strombolian explosions, which resulted in the identification of two sources representative of the distinct types of explosive explosions from two different vents (Chouet et al., 2003). The source mechanism is representative of two cracks dipping $\sim 60^{\circ}$ that are located approximately 220 and $260 \mathrm{~m}$, respectively, beneath the active craters, probably representing parts of an echelon system of fissures. Recently, a more detailed analysis (Chouet et al., 2008a, b) shows that each source consists of two intersecting cracks, in which one crack contributes the dominant component of seismic radiation and the other crack the subdominant component.

For the Stromboli volcano as well, muon radiography represents an independent technique for investigating the internal structure of the cone and revealing the location and extent of the conduits that feed the continuous explosions.

\section{Conclusions}

A knowledge of the internal structure of active volcanoes is of paramount importance for understanding their behaviour and mitigate volcanic hazard. Muon radiography represents an innovative tool for investigating the shallow structures of volcanoes and provides additional information independent from those obtained using conventional geophysical methods. In this paper we focused our attention on Vesuvius and Stromboli as good candidates for a muon radiography experiment. However, other volcanoes in the world, such as Montserrat, Teide, Piton de la Furnaise, La Soufriere, could benefit from a muon radiography. Previous experiences at Mt. Asama, Mt. West Iwate and ShowaShinzan (Japan) have shown the potentiality of the method.

Acknowledgments. We wish to thank the Laboratory of Geomatics and Cartography of Istituto Nazionale di Geofisica e Vulcanologia, Osservatorio Vesuviano (Napoli, Italy), for providing the Digital Elevation Model of Vesuvius. Moreover, we thank I. Yokoyama and B. Chouet for their critical revisions of the paper.

\section{References}

Bertagnini, A., N. Métrich, P. Landi, and M. Rosi, Stromboli volcano (Aeolian Archipelago, Italy): An open window on the deep-feeding system of a steady state basaltic volcano, J. Geophys. Res., 108(B7), 2336, doi:10.1029/2002JB002146, 2003.

Bonaccorso, A., S. Calvari, G. Garfì, L. Lodato, and D. Patanè, Dynamics of the December 2002 flank failure and tsunami at Stromboli volcano inferred by volcanological and geophysical observations, Geophys. Res. Lett., 30(18), 1941, doi:10.1029/2003GL017702, 2003.

Cassano, E., and P. La Torre, Geophysics, in Somma-Vesuvius, edited by Santacroce, R., Quaderni della Ricerca Scientifica, 114, 175-196, CNR, Roma, 1987.

Cella, F., M. Fedi, G. Florio, M. Grimaldi, and A. Rapolla, Shallow structure of the Somma-Vesuvius volcano from 3D inversion of gravity data, J. Volcanol. Geotherm. Res., 161, 303-317, 2007.

Chouet, B., P. Dawson, T. Ohminato, M. Martini, G. Saccorotti, F. Giudicepietro, G. De Luca, G. Milana, and R. Scarpa, Source mechanisms of explosions at Stromboli Volcano, Italy, determined from momenttensor inversion of very-long period data, J. Geophys. Res., 108(B1), doi:10.1029/2002JB001919, 2003.

Chouet, B., P. Dawson, and M. Martini, Shallow-conduit dynamics at Stromboli Volcano, Italy, imaged from waveform inversions, Geol. Soc., London, Special Publications, 307, 57-84, 2008a.

Chouet, B., P. Dawson, and M. Martini, Upper conduit structure and ex- 
plosion dynamics at stromboli, in The Stromboli volcano, an integrated study of the 2002-2003 eruption, edited by Calvari, S., S. Inguaggiato, G. Puglisi, M. Ripepe, and M. Rosi, Geophysical Monography, 182, 81-92, AGU, 2008b.

Cioni, R., A. Bertagnini, R. Santacroce, and D. Andronico, Explosive a activity and eruption scenarios at Somma-Vesuvius (Italy): Towards a new classi cation scheme, J. Volcanol. Geotherm. Res., 178(3), 331346, 2008.

Di Maio, R., P. Mauriello, D. Patella, Z. Petrillo, S. Piscitelli, and A. Siniscalchi, Electric and electromagnetic outline of Mt. Vesuvius structural setting, J. Volcanol. Geotherm. Res., 82, 219-238, 1998.

Macedonio, G., A. Neri, J. Mart', and A. Folch, Temporal evolution of ow conditions in sustained magmatic explosive eruptions, J. Volcanol. Geotherm. Res., 143(1-3), 153-172, 2005.

MU-RAY International Workshop, Università di Napoli, Dipartimento di Fisica, Napoli, Italy, 11-12 September 2008, http://muray. sica.unina.it/events/workshop_sep08, 2008.

Principe, C., M. Rosi, R. Santacroce, and A. Sbrana, Explanatory notes to the geological map, in Somma-Vesuvius, edited by Santacroce, R., Quaderni della Ricerca Scientifica, 114, 11-52, CNR, Roma, 1987.

Ricciardi, G. P., Vesuvio: Tu vuoi che io ti narri, DVD, Istituto Nazionale di Geo sica e Vulcanologia, Osservatorio Vesuviano, Napoli, Italy, 2005.

Santacroce, R., A general model for the behaviour of the Somma Vesuvius volcanic complex, J. Volcanol. Geotherm. Res., 17, 237-248, 1983.

Scaillet, B., M. Pichavant, and R. Cioni, Upward migration of Vesuvius magma chamber over the past 20,000 years, Nature, 455, 216-220, doi:10.1038/nature07232, 2008.

Scarpa, R., F. Tronca, F. Bianco, and E. Del Pezzo, High resolution velocity structure beneath Mt. Vesuvius from seismic array data, Geophys. Res. Lett., 29(21), 2040-2043, doi:10.1029/2002GL015576, 2002.

Scarpato, G., G. Ricciardi, F. Giudicepietro, and M. De Lucia, L'evoluzione morfologica del vesuvio in relazione alla sua storia eruttiva attraverso un'applicazione Web: SlideVes, Open File Report 6, Istituto Nazionale di Geo sica e Vulcanologia, Osservatorio Vesuviano, Napoli, Italy, http://www.ov.ingv.it/doc/ofr05006.pdf, 2005.

Tanaka, H. K. M., K. Nagamine, N. Kwamura, S. Nakamura, K. Ishida, and
K. Shimomura, Development of a two-fold segmented detection system for near horizontal cosmic-ray muons to probe the internal structure of a volcano, Nucl. Instr. Meth. A, 507, 657, 2003.

Tanaka, H. K. M., K. Nagamine, S. Nakamura, and K. Ishida, Radiographyc measurements of the internal structure of Mt. West Iwate with near-horizontal cosmic-ray muons and future developments, $\mathrm{Nucl}$. Instr. Meth. A, 555, 164-172, 2005.

Tanaka, H. K. M., T. Nakano, S. Takahashi, J. Yoshida, and K. Niwa, Development of an emulsion imaging system for cosmic-ray muon radiography to explore the internal structure of a volcano, Mt. Asama, Nucl. Instr. Meth. A, 575, 489-497, 2007a.

Tanaka, H. K. M., T. Nakano, S. Takahashi, J. Yoshida, H. Ohshima, T. Maekawa, H. Watanabe, and K. Niwa, Imaging the conduit size of the dome with cosmic-ray muons: The structure beneath Showa Shinzan lava dome, Japan, Geophys. Res. Lett., 34, L22311, doi:10.1029/2007GL031389, 2007b.

Tanaka, H. K. M., T. Nakano, S. Takahashi, J. Yoshida, M. Takeo, J. Oikawa, T. Ohminato, Y. Aoki, E. Koyama, H. Tsuji, and K. Niwa, High resolution imaging in the inhomogeneous crust with cosmic-ray muon radiography: The density structure below the volcanic crater oor of Mt. Asama, Japan, Earth Planet. Sci. Lett., 263, 104-113, 2007c.

Tibaldi, A., Multiple sector collapses at Stromboli volcano, Italy: how they work, Bull. Volcanol., 63(2/3), 112-125, 2001.

Zollo, A., P. Gasparini, J. Virieux, H. Le Meur, G. De Natale, G. Biella, E. Boschi, P. Capuano, R. de Franco, P. Dell'Aversana, R. De Matteis, I. Guerra, G. Iannaccone, L. Mirabile, and G. Vilardo, Seismic evidence for a low-velocity zone in the upper crust beneath Mount Vesuvius, Science, 274, 592-594, 1996.

Zollo, A., L. D'Auria, R. De Matteis, A. Herrero, J. Virieux, and P. Gasparini, Bayesian estimation of 2-D P-velocity models from active seismic arrival time data: Imaging the shallow structure of Mt. Vesuvius (Southern Italy), Geophys. J. Int., 151, 566-582, 2002.

G. Macedonio (e-mail: macedon@ov.ingv.it) and M. Martini 